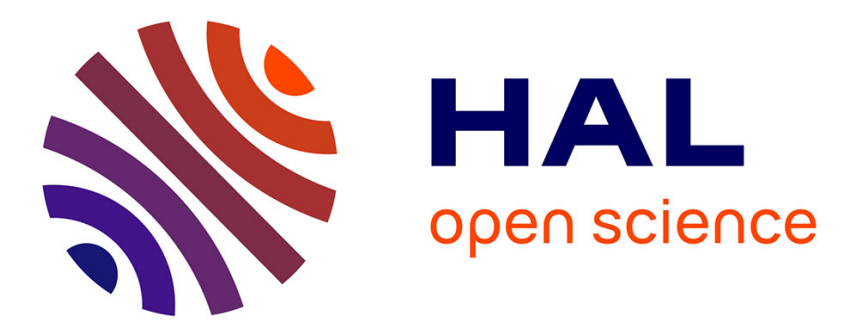

\title{
SEBS block copolymers as novel materials to design transdermal patches
}

Chiara Grazia Milena Gennari, Gaia Maria Giorgia Quaroni, Costantino

Creton, Paola Minghetti, Francesco Cilurzo

\section{To cite this version:}

Chiara Grazia Milena Gennari, Gaia Maria Giorgia Quaroni, Costantino Creton, Paola Minghetti, Francesco Cilurzo. SEBS block copolymers as novel materials to design transdermal patches. International Journal of Pharmaceutics, 2020, 575, pp.118975. 10.1016/j.ijpharm.2019.118975 . hal03112504

\section{HAL Id: hal-03112504 \\ https://hal.science/hal-03112504}

Submitted on 16 Jan 2021

HAL is a multi-disciplinary open access archive for the deposit and dissemination of scientific research documents, whether they are published or not. The documents may come from teaching and research institutions in France or abroad, or from public or private research centers.
L'archive ouverte pluridisciplinaire HAL, est destinée au dépôt et à la diffusion de documents scientifiques de niveau recherche, publiés ou non, émanant des établissements d'enseignement et de recherche français ou étrangers, des laboratoires publics ou privés. 


\title{
SEBS block copolymers as novel materials to design transdermal patches
}

\author{
Chiara Grazia Milena Gennari ${ }^{\mathrm{a}, 1}$, Gaia Maria Giorgia Quaroni ${ }^{\mathrm{a}, 1,2}$, Costantino Creton ${ }^{\mathrm{b}, \mathrm{c}}$, \\ Paola Minghetti ${ }^{\mathrm{a}}$, Francesco Cilurzo ${ }^{\mathrm{a}, *}$ \\ ${ }^{a}$ Department of Pharmaceutical Sciences, Università degli Studi di Milano, via G. Colombo, 71, 20133 Milano, Italy \\ ${ }^{\mathrm{b}}$ Laboratory of Soft Matter and Engineering Sciences, CNRS UMR 7615, École Supérieure de Physique et de Chimie Industrielles de la Ville de Paris (ESPCI), ParisTech, PSL \\ Research University, 10 rue Vauquelin, F-75231 Paris cedex 05, France \\ ${ }^{\mathrm{c}}$ IMM, UPMC Univ Paris 06, Sorbonne-Universités, 10 rue Vauquelin, F-75231 Paris cedex 05, France
}

\section{A R T I C L E I N F O}

\section{Keywords:}

SEBS

Pressure-sensitive adhesives

Transdermal patches

Rheology

Skin permeation

Drug release

\begin{abstract}
A B S T R A C T
Styrene-block-(ethylene-co-butylene)-block-styrene (SEBS) copolymers are biocompatible elastomers with outstanding stability to UV radiation. This work addresses the potentialities of this class of elastomers for the development of transdermal patches. The influence of SEBS molecular weight, plasticizer and tackifier type on rheological pattern, debonding mechanisms, adhesive properties (i.e., tack, shear and peel adhesion) as well as on the in vitro biopharmaceutical performances (i.e., drug release and skin permeability) was investigated using ibuprofen as model drug. The relationships between the linear and non-linear rheological properties and the main adhesive and biopharmaceutical properties of the prepared patches have been demonstrated. The higher the viscous component of the matrix, the lower its cohesiveness and the faster the drug release rate. The in vitro skin permeability of ibuprofen was not limited by the polymeric matrix, even if compared to the commercial reference product. In conclusion, SEBS copolymers are suitable materials to design drug in-adhesive patches. In particular, SEBS-low molecular weight is the polymer worthy of consideration because of its favorable viscoelastic behavior.
\end{abstract}

\section{Introduction}

Transdermal patches are nowadays designed as drug in adhesive systems in which a drug loaded pressure sensitive adhesive is sandwiched between a protective liner and a backing layer or outer covering (Cilurzo et al., 2012). The former is removed and discharged immediately before the application of the patch to the skin, the latter prevents the adhesion to the cloths and the loss of drug through the backing surface. The transdermal patches are usually produced by solvent casting or, alternatively, by hot-melt methods. Basically, a slurry is spread on the protective layer and then the dry/cold adhesive layer is coupled with backing layer.

Thermoplastic elastomers such as styrenic block copolymers are widely used in PSAs because of their unique structure, which offer advantages in processing. They consist of two polystyrene end-blocks and a linear aliphatic mid-block. These end-blocks and mid-blocks are completely incompatible and therefore the material is arranged into domains on a $20-50 \mathrm{~nm}$ level. Since each molecule of a tri-block polymer has styrene on each end, the styrenic domains comprise several molecules. This association of end-blocks acts as a multifunctional physical crosslinker effectively giving a flexible and elastic material.

The elasticity of styrene block copolymers is due to the thermodynamic incompatibility between the polystyrene end-blocks and the elastomer midblock, creating a two-phase structure consisting of polystyrene "domains" dispersed in an elastomeric matrix. The exact morphology of the two-phase structure and the mechanical properties depend on the molecular structure of both phases and in particular on their molecular weights (Bates and Fredrickson, 1990; Creton et al., 2005, 2009).

Considering these characteristics, styrene-based block copolymers are the perfect base for hot melt adhesives (Derail et al., 2004; Kim et al., 2012): they are strong, rubbery solids at ambient temperature, but become viscous liquids at high temperatures and this change of state is reversible.

Among these copolymers, styrene-isoprene-styrene (SIS) copolymers were widely studied for the design of pressure sensitive adhesives (Minghetti et al., 2004) suitable for the preparation of both transdermal patches (Ma et al., 2013) and medical devices (Jin et al., 2016). The 
Table 1

Placebo and drug-loaded formulation compositions (\%, w/w).

\begin{tabular}{|c|c|c|c|c|c|c|c|}
\hline Form. Code & SEBS-L & SEBS-M & SEBS-H & Regalite $^{\mathrm{TM}} \mathrm{H} 1100$ & Eastotac $^{\mathrm{TM}} \mathrm{H} 100 \mathrm{~W}$ & Paraffin oil & IB \\
\hline L-R & 10 & - & - & 40 & - & 50 & - \\
\hline L-E & 10 & - & - & - & 40 & 50 & - \\
\hline M-R & - & 10 & - & 40 & - & 50 & - \\
\hline M-E & - & 10 & - & - & 40 & 50 & - \\
\hline $\mathrm{H}-\mathrm{R}$ & - & - & 10 & 40 & - & 50 & - \\
\hline $\mathrm{H}-\mathrm{E}$ & - & - & 10 & - & 40 & 50 & - \\
\hline L-R_IB & 9 & - & - & 36 & - & 45 & 10 \\
\hline L-E_IB & 9 & - & - & - & 36 & 45 & 10 \\
\hline$M-R \_I B$ & - & 9 & - & 36 & - & 45 & 10 \\
\hline M-E_IB & - & 9 & - & - & 36 & 45 & 10 \\
\hline H-R_IB & - & - & 9 & 36 & - & 45 & 10 \\
\hline H-E_IB & - & - & 9 & - & 36 & 45 & 10 \\
\hline
\end{tabular}

adhesive properties have been conferred by compounding the SIS with paraffin oil and an aliphatic resin (Jagisch and Tancrede, 1989). Moreover, because of their chemical structure, SIS copolymers need a large amount of antioxidants to improve their stability (Chanda and Roy, 2007). Conversely, styrene-block-(ethylene-co-butylene)-blockstyrene (SEBS) copolymers, being hydrogenated derivatives, are elastomers with outstanding stability to UV radiations and well-known biocompatibility (Costa et al., 2015; Hou et al., 2014). Moreover, their compounding with plasticizer(s) and tackifier(s) results in a hot melt pressure sensitive adhesive with a very high creep resistance (Kim et al., 2012).

Taking into account all these considerations, SEBS copolymers appear as good potential candidates for the design of transdermal patches and/or medicated plasters. Nevertheless, the performances of the system obtained by the casting technique has not been well investigated and the ability of the compounded SEBS based pressure sensitive adhesive to release a loaded drug is unknown.

The aim of this work was to design a pressure sensitive adhesive made of SEBS in order to demonstrate the potentialities of such class of materials in the development of transdermal patches.

The adhesive properties were conferred using a low molecular weight, but high glass transition temperature hydrocarbon resin as tackifier and a liquid paraffin as plasticizer (***Pagani et al., 2006).

The PSAs were designed by using SEBS with different average molecular weights and, since tackifiers are crucial components for tuning the initial bonding of a PSA (Nakajima et al., 1992), two resins, with different structure, glass transition temperature $\left(\mathrm{T}_{\mathrm{g}}\right)$ and molecular weight were added.

The linear viscoelastic properties of the formulated materials were characterized with a rheometer and the adhesive properties were characterized with a specially designed probe tack instrument (Lakrout et al., 1999) focusing on the debonding behavior from a steel surface under different operating conditions. The debonding of PSAs from a rigid surface often occurs with the formation of a fibrillar structure. Since the energy is only dissipated rather rapidly when the fibrils are detached from the surface, it is essential to characterize the elastic properties of these adhesives not only in the linear viscoelastic regime, but also in the large strain non-linear elastic domain (Creton et al., 2009; Deplace et al., 2009). We have therefore also performed tensile tests of adhesive films based on SEBS. The in vitro biopharmaceutical performances of patches were assessed using ibuprofen, as a model drug.

\section{Materials and methods}

\subsection{Materials}

Pharmaceutical grade SEBS are available on the market under the trade name of Europrene SOL $\mathrm{TH}^{\circledast}$. Three types of SEBS, were kindly donated by Versalis SpA (San Donato Milanese, Italy): Europrene SOL
$\mathrm{TH}^{\circledast} 2311$ (triblock, 30\% bound styrene, average molecular weight $45.61 \mathrm{kDa}, \mathrm{M}_{\mathrm{n}} 43,65 \mathrm{kDa}, \mathrm{M}_{\mathrm{w}} / \mathrm{M}_{\mathrm{n}}=1.04$, SEBS-L), Europrene SOL TH ${ }^{\circledast}$ 2312 (triblock, 30\% bound styrene, average molecular weight $64.23 \mathrm{kDa}, \mathrm{M}_{\mathrm{n}} 59,82 \mathrm{kDa}, \mathrm{M}_{\mathrm{w}} / \mathrm{M}_{\mathrm{n}}=1.07$, SEBS-M), and Europrene SOL TH ${ }^{\circledR} 2315$ (triblock, 32\% bound styrene, average molecular weight $176.35 \mathrm{kDa}, \mathrm{M}_{\mathrm{n}} 155,87 \mathrm{kDa}, \mathrm{M}_{\mathrm{w}} / \mathrm{M}_{\mathrm{n}}=1.13$, SEBS-H). In order to make the system adhesive it was necessary to add a tackifier. The hydrocarbon resins Regalite ${ }^{\mathrm{TM}} \mathrm{R} 1100$ (ring and ball softening point $=100{ }^{\circ} \mathrm{C}$, glass transition temperature $=50{ }^{\circ} \mathrm{C}$, cloud point $=78{ }^{\circ} \mathrm{C}$, molecular weight $=850 \mathrm{~g} / \mathrm{mol}$ ) and Eastotac $^{\mathrm{TM}} \mathrm{H} 100 \mathrm{~W}$ (ring and ball softening point $=100{ }^{\circ} \mathrm{C}$, glass transition temperature $=41{ }^{\circ} \mathrm{C}$, cloud point $=81{ }^{\circ} \mathrm{C}$, molecular weight $=1000 \mathrm{~g} / \mathrm{mol}$ ) were donated from Eingemann\&Veronelli Spa (Rho, Italy). Paraffin oil was obtained from Carlo Erba (Milan, Italy). In order to produce transdermal patches a polyester film was chosen as backing layer, while a polyester siliconized film Saint Gobain (thickness $120 \mu \mathrm{m}$ ) was used as a release liner. Sibuprofen (IB) was purchased from Dipharma Francis (Baranzate, Italy). Toluene was chosen as solvent and it was purchased by Sigma Aldrich (Milan, Italy). All the solvents were of analytical grade.

\subsection{Preparation of the formulations}

The SEBS polymers were dissolved in toluene, and the mixtures were continuously maintained under stirring with a magnetic bar at room temperature for $1 \mathrm{~h}$. Then, the other components of the formulation were added, and the solution was continuously maintained under stirring with a magnetic bar at room temperature for $23 \mathrm{~h}$. When the drug-loaded formulations were prepared, IB was added in the polymeric solution, before adding tackifier and oil. PSAs and patches were prepared only after $24 \mathrm{~h}$ in order to reduce air bubbles formed during the stirring stage. A pre-formulation study was performed to achieve the final compositions of the formulations, which are illustrated in Table 1.

\subsection{Rheological properties in the linear regime}

The rheological parameters were determined on a Discovery Hybrid Instrument HR-3 (TA Instruments), by using a parallel crosshatched plate geometry (diameter: $22 \mathrm{~mm}$ ). In order to obtain equilibrated samples of about $2 \mathrm{~mm}$ of thickness, a special cup-shaped sample holder $(6 \times 5 \mathrm{~cm})$ made of Teflon was used. The solution was then poured in the cup and the sample was dried in the sample holder. A 2-steps drying process was used: first, the adhesive matrices were dried under a glass cover for $24 \mathrm{~h}$ at room temperature and subsequently in an oven at $45{ }^{\circ} \mathrm{C}$ under vacuum for $24 \mathrm{~h}$. After 7 days, necessary for matrix maturation, each sample was cut (diameter: $22 \mathrm{~mm}$ ) by using a punch. Strain sweep measurements were performed at $6.28 \mathrm{rad} / \mathrm{s}(1 \mathrm{~Hz})$ in order to define the linear viscoelastic region (LVR). Once the LVR was set, a frequency sweep deformation in the range $10^{-2}-10^{2} \mathrm{rad} / \mathrm{s}$ was applied to the sample. The strain value was in the LVR. Each sample 
was analyzed first at $25{ }^{\circ} \mathrm{C}$, and then at $32{ }^{\circ} \mathrm{C}$. Storage modulus ( $\left.\mathrm{G}^{\prime}\right)$, loss modulus $\left(G^{\prime \prime}\right)$ and phase angle $(\delta)$ were used to characterize the samples. Each experiment was performed twice to test data reproducibility.

\subsection{Texture analysis}

In order to obtain a dry matrix of $180-200 \mu \mathrm{m}$ thickness, $3 \mathrm{~mL}$ of polymeric mixture were deposited on a standard glass slide $\left(2.6 \times 10 \times 0.2 \mathrm{~cm}^{3}\right)$, previously cleaned and activated by a plasma technique. A 2-steps drying process was used: first, PSAs were dried under a glass cover for $24 \mathrm{~h}$ at room temperature and subsequently in an oven at $45{ }^{\circ} \mathrm{C}$ under vacuum for $24 \mathrm{~h}$. The adhesive matrix final thickness was evaluated by a white light scattering technique with an optical profilometer (Microsurf 3D, Fogale nanotech). Probe tack experiments were performed on a custom-designed apparatus adapted on an MTS 810 hydraulic testing machine, allowing the simultaneous observation of the debonding process through a transparent glass substrate (Lakrout et al., 1999). A circular flat ended probe was brought into contact with the adhesive layer at a constant velocity $(30 \mu \mathrm{m} / \mathrm{s})$. Once the probe and the sample came into contact, a compressive force of $30 \mathrm{~N}$ was applied. The probe was maintained in contact with the adhesive for $10 \mathrm{~s}$. At the end of the contact time, the probe was separated from the adhesive by retracting it at a predefined speed, namely 10,100 and $1000 \mu \mathrm{m} / \mathrm{s}$. The probe was made of stainless steel with a diameter of $9.7 \mathrm{~mm}$. The probe flatness was well-controlled by polishing it with several grades of abrasive paper. The entire probe tack set-up was enclosed in a controlled-temperature chamber to perform the experiments at room temperature $\left(25 \pm 0.5^{\circ} \mathrm{C}\right)$ and at skin surface temperature $\left(32 \pm 0.5{ }^{\circ} \mathrm{C}\right)$. The whole force-distance curve was recorded. The detachment force and the elongation at break were measured and expressed in Newtons $(\mathrm{N})$ and millimeters $(\mathrm{mm})$, respectively. Since the results are influenced by the PSA thickness, the forcedistance curve was converted into a stress-strain curve. The nominal tensile stress $(\sigma)$ and strain $(\varepsilon)$ were calculated according to the following equations:

$\sigma=F / A$

$\varepsilon=\left(h_{t}-h_{0}\right) / h_{0}$

$\mathrm{F}$ is the force registered during the detachment, $\mathrm{A}$ is the surface area of the probe that is in contact during the compression stage, as determined from the video streaming, $h_{t}$ is the adhesive elongation at time $t$ and $h_{0}$ is the adhesive layer initial thickness. The Adhesion energy $\left(\mathrm{W}_{\mathrm{adh}}\right)$ can then be evaluated as the integral of the $\sigma-\varepsilon$ curve multiplied by the initial thickness.

To evaluate the fracture occurring during the debonding process all tests were filmed and recorded through a $45^{\circ}$ mirror. For each formulation and for each experimental condition three tests were carried out.

\subsection{Non-linear elastic properties}

Tensile tests under large strain were carried out in a standard tensile testing machine (Instron model 5565), equipped with a $10 \mathrm{~N}$ load cell and a non-contact video extensometer (SVE), to measure the local strain near the center of the sample. Rectangular samples of $2 \mathrm{~mm}$ thick, $5 \mathrm{~mm}$ wide, and $20 \mathrm{~mm}$ long (length between the clamps) were cut with a die-cutter. They were prepared at the desired thickness in the same way as the samples used for the rheological tests. Tensile tests were performed on the same formulations tested at room temperature since rheological measurements showed that the behavior of the SEBS-sample doesn't change when increasing the temperature from $25{ }^{\circ} \mathrm{C}$ to $32{ }^{\circ} \mathrm{C}$. The experiments were carried out using two different cross-head velocities (kept constant): $0.833 \mathrm{~mm} / \mathrm{s}$ and $8.33 \mathrm{~mm} / \mathrm{s}$; these velocities were chosen in order to be approximately equivalent to the strain rate applied to the materials in the texture analysis. Two white spots were drawn on the sample to follow the displacement with the laser extensometer. Two tests were performed for each sample at a given strain rate to ensure reproducibility.

During the test, force and displacement from the cross-head were measured. In addition, the extensometer measures the displacement of the white spots. A comparison of the two nominal strains obtained from the cross-head and of the extensometer ensured that no slippage occurred during the experiments. The following parameters were determined: nominal stress $\sigma_{\mathrm{N}}$, calculated by dividing the force by the original cross-section area of the specimen and expressed in force per unit area (MPa), and $\lambda$, that is the stretch or extension ratio calculated by dividing the length of the specimen by the initial length of the specimen.

\subsection{Patches preparation}

Patches were prepared by casting, using a laboratory-coating unit Mathis LTE-S(M) (Mathis, CH), equipped with a doctor knife. The coating thickness was set at $250 \mu \mathrm{m}$ in order to obtain a dry matrix of about $50 \mu \mathrm{m}$. The mixture was spread on the backing layer, dried at $40{ }^{\circ} \mathrm{C}$ for $20 \mathrm{~min}$, and covered with the release liner. To evaluate the final matrix thickness a MI $1000 \mu \mathrm{m}$ (ChemInstrument, USA) was used. Samples were sealed in a well-closed airtight container and stored at $25 \pm 0.1{ }^{\circ} \mathrm{C}$ until use.

\subsection{Inclined ball-tack test}

The inclined ball tack test probes the ability of a patch to quickly adhere to a stainless-steel surface. In this test, balls characterized by different diameters are rolled on the adhesive surface of a patch placed onto an inclined ramp; the largest ball that stops on the patch determines the tack value. According to the "Inclined ball tack testing" reported in the Japanese Pharmacopeia XVII (JP), a plane having an inclination angle of $30^{\circ}$ was used. Samples were cut in order to obtain specimens wider than $10 \mathrm{~mm}$ and longer than $70 \mathrm{~mm}$. Each specimen was fixed in the prescribed position on the ramp with the adhesive layer side up. The upper and the lower ends of the specimen were covered with clean sheets of paper, leaving $50 \mathrm{~mm}$ of adhesive free at the central position. The balls must be able to roll down without slipping. Several hard steel balls (from no. 2 to no. 32, JP XVII) were used. The higher the ball number, the larger the diameter and, therefore, the greater the weight. Before running, each ball was cleaned by rinsing it with acetone and wiping it dry with absorbent cleaning material followed by air drying for at least $10 \mathrm{~min}$. Finally, each ball was rolled over the inclined plane from the top of the ramp onto the adhesive tape. Specimens were changed for each run. The number (No.) of the largest ball that stops on the adhesive represents the value of the inclined ball tack test. The assay was performed in triplicate.

\subsection{Shear adhesion}

Shear adhesion tests were performed by using an 8 Bank Oven Shear HT8 Instrument (ChemInstruments, Ichemco, Cuggiono, Italy), in agreement with an internal method described by Cilurzo et al. (2013). The adhesive sample was pressed onto the stainless-steel test panel with a bonding area of $2.5 \times 2.5 \mathrm{~cm}^{2}$ by a double pass of a $2.04 \mathrm{~kg}$ roller. A mass of $500 \mathrm{~g}$ was hung at the end of each sample. To perform tests at $32{ }^{\circ} \mathrm{C}$ a controlled-temperature chamber was used. Each result, namely the time required to completely detach the sample from the test panel, is expressed as the mean \pm standard deviation of six determinations for each formulation.

\subsection{Peel adhesion $180^{\circ}$ test}

Peel adhesion measures the patch adherence when peeled at $180^{\circ}$ angle to a standard steel panel. Peel strength was measured on a tensile 
machine equipped with a $50 \mathrm{~N}$ cell (Instron 5965, ITW Test and Measurement Italia S.r.L., Trezzano sul Naviglio, Italy) at room temperature. Tests were performed according to an internal method (Cilurzo et al., 2013).

For each formulation, samples were run using a stainless-steel panel, at a peel angle of $180^{\circ}$ and peel speed of $300 \mathrm{~mm} / \mathrm{min}$. The average force was calculated as the arithmetical mean of the values of the linear portion of the curve and the results are expressed as the mean \pm standard deviation of six determinations for each formulation. The peel values are expressed in $\mathrm{cN}$ per centimeter width of the adhesive patch under test.

\subsection{Cold flow}

Cold flow represents the migration of the adhesive matrix outside the edge of the backing layer during the storage and involves drug leakage from the edge of membrane-controlled patch. It occurs if the matrix flows like a very viscous liquid between the backing layer and the release liner during the storage (Quaroni et al., 2017). Circular samples (matrix and backing layer) were cut by using a punch (diameter: $32 \mathrm{~mm}$ ), maintaining the whole release liner. After three months of storage in a sealed container impervious to water and humidity at $40 \pm 1{ }^{\circ} \mathrm{C}$, samples were evaluated in terms of migration of the adhesive matrix on the release liner. The dimensional changes were measured using a graph paper and cold flow was considered negligible if the matrix was not visually detectable outside the backing layer.

The analyses were performed in triplicate.

\subsection{Drug content}

To determine IB amount loaded in the patches, a specimen of $2.54 \mathrm{~cm}^{2}$, after release liner removing, was first weighed and then dissolved in $50 \mathrm{~mL}$ of methanol. To support the complete solubilization of the adhesive matrix and the active principle, the sample was sonicated for $1 \mathrm{~h}$ and then left at rest overnight. The solution was filtered through a $0.45 \mu \mathrm{m}$ polypropylene filter (VWR International, Milan, Italy), diluted with mobile phase $(1: 9 \mathrm{v} / \mathrm{v})$ and assayed by HPLC, according to the method reported below. Each value represents the average of three determinations for each formulation.

\subsection{Dissolution test}

The IB release rate was studied by using an apparatus SR8 PLUS Dissolution test station (Hanson Research, CA, USA) according to the "Dissolution test for transdermal patches" of European Pharmacopoeia 9.2, 2017.

A sample of $8.04 \mathrm{~cm}^{2}$ was cut and placed flat on the disk with the release liner surface facing up. The backing layer was attached on the disk by using a cyanoacrylate adhesive and the release liner was removed. Each vessel was filled with $300 \mathrm{~mL}$ of PBS buffer (pH 7.4), the water bath temperature was maintained at $32 \pm 0.5^{\circ} \mathrm{C}$ and the paddle speed was set at $25 \mathrm{rpm}$. Samples $(5 \mathrm{~mL})$ were collected at predetermined intervals and assayed by HPLC, according to the methods reported in paragraph 2.13. An equal volume of fresh medium was immediately added to maintain the dissolution volume.

The release rate constant was calculated according to Higuchi's equation as follows:

$M_{t} / M_{\infty}=k t^{0.5}$

where $M_{t}$ is the amount of drug released at time $t, M_{\infty}$ is the drug loading in the matrix and $k$ is the release rate constant expressed as $\mathrm{h}^{0.5}$. Each value represents the average of three measurements.

\subsection{In vitro skin permeation study}

Since pig ear skin shows similar histological and physiological characteristics and close permeability properties with respect to human skin (Engesland et al., 2016; Campani et al., 2016), it was selected to study IB-permeation profiles from SEBS-patches. This skin used was obtained from the ears of different pigs, which were kindly provided by a local slaughterhouse (Milan, Italy).

The pig ear skin was separated from the underlying cartilage, cut into squares of about $3.5 \mathrm{~cm}^{2}$ and sealed in evacuated plastic bags and frozen at $-20{ }^{\circ} \mathrm{C}$. Before the experiments, the samples were equilibrated at room temperature for $1 \mathrm{~h}$.

The integrity of all tissue samples was assessed by measuring their electrical resistance (voltage: $100 \mathrm{mV}$, frequency: $100 \mathrm{~Hz}$; Agilent 4263B LCR Meter, Microlease, Cernusco sul Naviglio, Italy) (Gennari et al., 2017).

The permeation experiments were performed using modified Franz cells under occlusive conditions. They have a diffusion area of $0.636 \mathrm{~cm}^{2}$ and a receptor compartment volume of approximately $5 \mathrm{~mL}$. This compartment was filled with physiological solution. A patch sample $\left(2.54 \mathrm{~cm}^{2}\right)$ was applied onto pig-ear with slight pressure. The patch-skin system was carefully mounted on the lower part of the Franz cell with the patch facing upward. The upper and lower parts of the vertical Franz cell were sealed with Parafilm ${ }^{\circledR}$ and fastened together by means of a clamp. The system was kept at $37 \pm 1{ }^{\circ} \mathrm{C}$ by means of a circulating water bath so that the skin surface temperature was at $32 \pm 1{ }^{\circ} \mathrm{C}$ and the receiver medium was continuously maintained under stirring with a magnetic bar. At predetermined interval times (1, 3, 5, 7 and 24 h) $200 \mu \mathrm{L}$ samples were withdrawn from the receptor compartment and an equivalent volume of fresh receiver medium was added. Sink conditions were maintained throughout the experiment. Samples were analyzed by HPLC according to the method described below.

The cumulative amount permeated through the pig ear skin per unit of area was calculated from the concentration of IB in the receiving medium and plotted as a function of time. The main calculated permeation parameters were the sum of the amount of drug permeated through the skin $\left(\mathrm{Q}_{24 \mathrm{~h}}\right)$, expressed as $\mu \mathrm{g} / \mathrm{cm}^{2}$, and the steady flux $(J)$, expressed as $\mu \mathrm{g} / \mathrm{cm}^{2} \mathrm{~h}$ and determined as the slope of the linear portion of the plot. The results of each permeation experiments are expressed as the mean \pm standard deviation of three replicates for each formulation.

\subsection{Drug assay}

The IB concentrations were quantified by HPLC analysis (Agilent HP 1100, Chemstation, Hewlett Packard, Santa Monica, USA). $20 \mu \mathrm{L}$ sample was injected at $25{ }^{\circ} \mathrm{C}$ on a HyperClone ${ }^{\mathrm{TM}} 5 \mu \mathrm{m}$ BDS C18 130, $150 \mathrm{~mm} \times 4.6 \mathrm{~mm}$ (Phenomenex, Torrance, CA) column. The composition of the mobile phase was acetonitrile/water pH $2.6(60 / 40, \%$ $\mathrm{v} / \mathrm{v})$. The flow rate was $1.5 \mathrm{~mL} / \mathrm{min}$. The wavelength was set at $230 \mathrm{~nm}$. IB concentration was determined from a standard calibration curves in the $0.1-50 \mu \mathrm{g} / \mathrm{mL}$ range.

\subsection{Statistical analysis}

The performances of the patches in terms of drug release rates and adhesive properties were compared by analysis of the variance followed by Turkey post-analyses (Daniel's XL Toolbox 6.70). The level of significance was taken as $p<0.05$.

\section{Results and discussion}

\subsection{Pressure sensitive adhesive characterization}

Texture experiments were performed not only to evaluate the instant adhesion properties of the PSAs, but also their debonding mechanisms. The compression stress (0.4 MPa) applied during the experiment was selected after performing different tests at different 


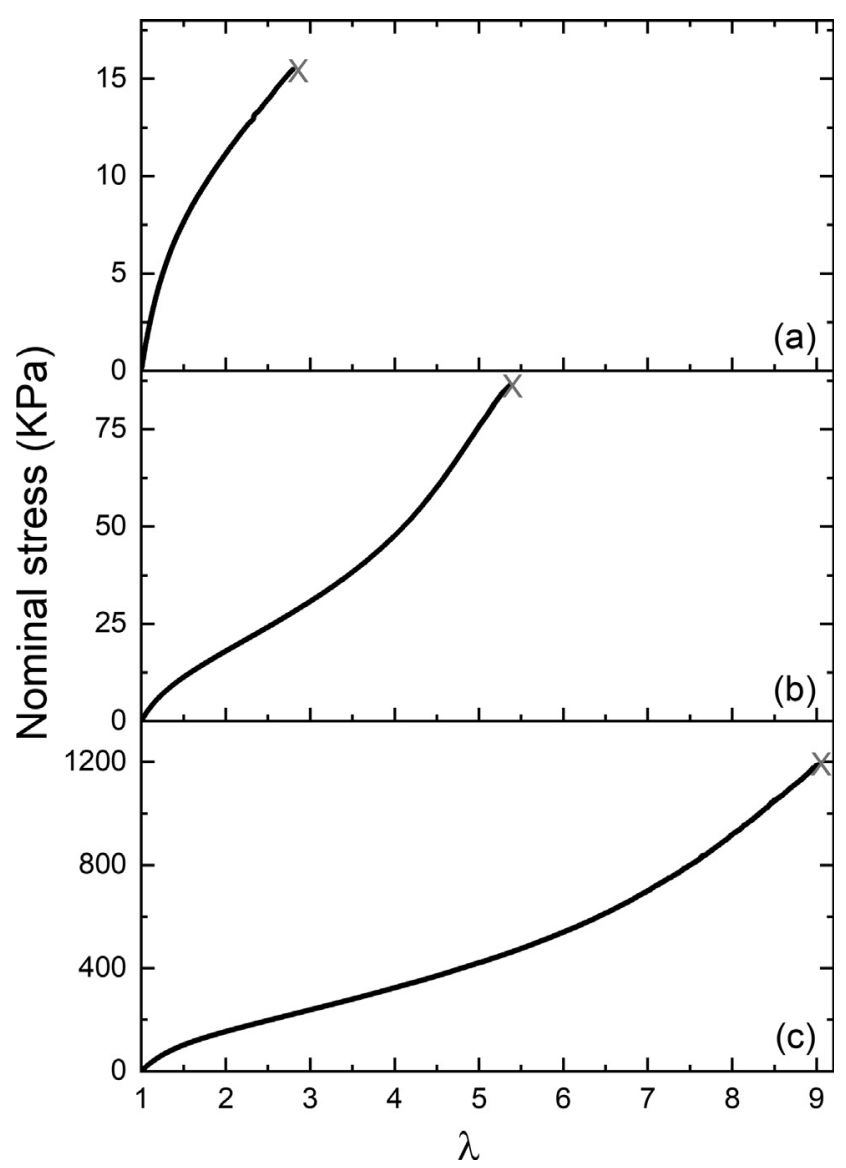

Fig. 3. Effect of SEBS-molecular weight on the stress-lambda curves in the nonlinear tensile experiments. Formulations were tested at $25{ }^{\circ} \mathrm{C}$ and $5 \mathrm{~mm} / \mathrm{s}$ as cross-head velocity. (a: formulation L-R, b: formulation $\mathrm{M}-\mathrm{R}$, c: formulation $\mathrm{H}-$ R).

(Fig. 3), due to the structure of the matrices: they are composed of styrene domains and soft deformable isoprene regions swollen with resin and plasticizer (Creton et al., 2005). All the formulations, independent of the molecular weight of SEBS, exhibited a pronounced softening at intermediate strains, which is an indication of a notable viscoelastic behavior. The formulation based on SEBS-L did not display any strain hardening at large strain before breaking and failed at a relatively low extension of $\lambda=3$ (Fig. 3).

The formulations based on SEBS-M and SEBS-H on the other hand were much more extensible and showed a softening stage followed by hardening. In particular, the SEBS-H is significantly stiffer with a stress at break of more than $300 \mathrm{kPa}$ as opposed to 80 and $14 \mathrm{kPa}$ for SEBS-M and SEBS-L respectively.

\subsection{Placebo patches characterization}

The thickness of both placebo and drug-loaded matrices was in the 49-55 $\mu \mathrm{m}$ range. Considering the accuracy of the instrument, all the matrices can be considered similar.

In terms of adhesive properties, the shear adhesion measures the ability of a PSA to adhere to a standard steel panel under constant stress (Cilurzo et al., 2012). All the recorded values felt in an acceptable range since they were higher than values reported in literature for transdermal patches (Minghetti et al., 2001). No significant differences were observed in the shear adhesion values of formulations based on SEBS-L and SEBS-M (Table 2). On the contrary, as expected, formulations H-R and $\mathrm{H}-\mathrm{E}$ showed higher values than the corresponding formulations based on SEBS with lower molecular weights.

The absence of differences among SESB-L and SEBS-M can be
Table 2

Adhesive properties of placebo patches: shear adhesion, peel adhesion and tack (ball no.) evaluated by inclined rolling ball test.

\begin{tabular}{llll}
\hline Form. Code & Shear adhesion $(\mathrm{min})$ & Peel adhesion $(\mathrm{cN} / \mathrm{cm})$ & Ball No. \\
\hline L-R & $61.7 \pm 14.6$ & $37.8 \pm 9.3$ & 5 \\
L-E & $57.6 \pm 5.2$ & $38.0 \pm 9.0$ & 5 \\
M-R & $57.2 \pm 4.1$ & $26.4 \pm 2.6$ & 8 \\
M-E & $38.4 \pm 24.1$ & $25.8 \pm 3.3$ & 8 \\
H-R & $101.3 \pm 8.2$ & $48.0 \pm 9.7$ & 12 \\
H-E & $277.5 \pm 41.2$ & $48.6 \pm 10.3$ & 12 \\
\hline
\end{tabular}

explained considering that the patches M-R and M-E detached adhesively (i.e., the adherent plate was clean after the detachment): as a consequence, the shear adhesion results cannot be considered as a true measure of the internal strength of these formulations (Cilurzo et al., 2012). On the contrary, for formulations L-R and L-E a matrix print on the steel panel test was observed after the detachment of the patches.

The results obtained from the rheological oscillatory tests in the linear regime performed to assess the PSA viscoelasticity can help to explain the different behavior among SEBS-H or SEBS-M and SEBS-L. The rheological measurements showed that the materials made from SEBS-L behaved as viscoelastic fluids with $G^{\prime}$ and $G^{\prime \prime}$ varying markedly with frequency, while those prepared by SEBS-M and SEBS-H behave like moderately viscoelastic gels. (Fig. 4).

This means that formulations L-R and L-E possess the appropriate balance between cohesion and adhesion for this particular application. In other words, they behaved as viscoelastic fluids, guaranteeing a reasonable resistance to shear, and as viscous liquids, able to dissipate energy when peeled off the substrate (Deplace et al., 2009). On the basis of these considerations, the detachment behavior of formulations L-R and L-E can be attributed to a polymer molecular disentanglement within the adhesive, resulting in a cohesive failure. On the contrary, the more elastic materials (based on SEBS-M and SEBS-H), under a shear stress, separate at the interface leaving no traces of matrix residues on the steel panel test.

The good cohesive properties of the prepared adhesive matrices are further supported by the lack of cold flow after storage at $40{ }^{\circ} \mathrm{C}$ over 3 months, in agreement with the elastic properties of these materials both in the linear viscoelastic region and in the large strain non-linear elastic domain. Indeed, it was demonstrated in a previous work that patches present cold flow when the polymeric matrices show a more viscous character (Quaroni et al., 2017). Moving the attention toward the tackifiers, an influence of their molecular weight can be noted even

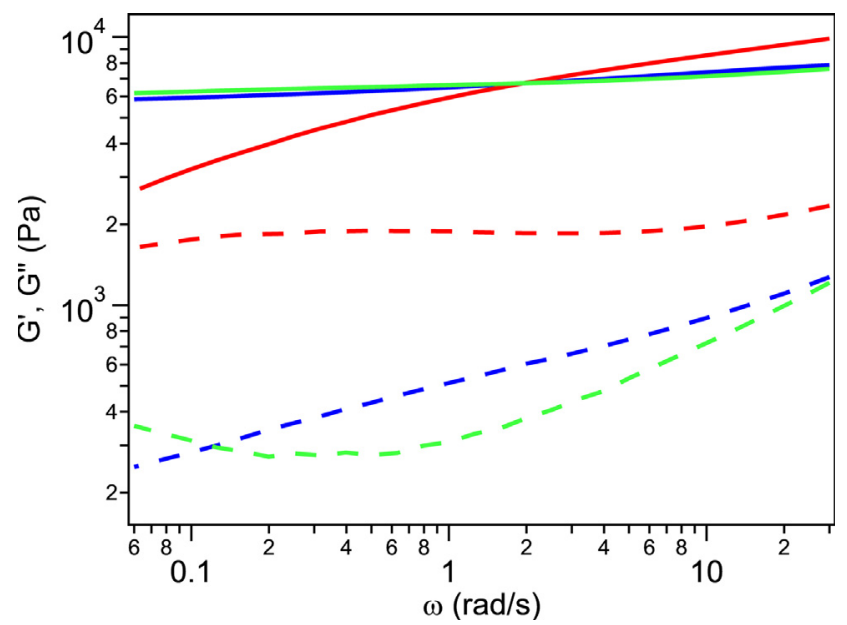

Fig. 4. Evolution of $\mathrm{G}^{\prime}$ and $\mathrm{G}^{\prime \prime}$ with frequency. Tests were performed at $25{ }^{\circ} \mathrm{C}$ (red line: L-R, green line: M-R, blue line: H-R). (For interpretation of the references to colour in this figure legend, the reader is referred to the web version of this article.) 
Table 3

Elastic modulus $\left(\mathrm{G}^{\prime}\right)$ of placebo formulations as a function of frequency.

\begin{tabular}{|c|c|c|c|}
\hline \multirow[t]{2}{*}{ Form } & \multicolumn{3}{|l|}{$\mathrm{G}^{\prime}(\mathrm{kPa})$} \\
\hline & $0.05 \mathrm{rad} / \mathrm{s}$ & $6.28 \mathrm{rad} / \mathrm{s}$ & $100 \mathrm{rad} / \mathrm{s}$ \\
\hline L-R & 2.71 & 8.03 & 11.58 \\
\hline L-E & 7.93 & 11.54 & 15.18 \\
\hline M-R & 6.39 & 7.15 & 9.28 \\
\hline M-E & 6.16 & 6.79 & 9.05 \\
\hline H-R & 6.07 & 6.72 & 5.21 \\
\hline
\end{tabular}

if this effect resulted statistically significant only in the formulations made with SEBS-H $(p<0.05)$. In particular, as expected, the higher the molecular weight of the hydrogenated aliphatic resin used as tackifier, the higher the shear adhesion values.

Again, all the formulations satisfied Dahlquist's criterion (Table 3), according to which a good PSA has to show an elastic modulus determined at the bonding frequencies $(6.28 \mathrm{rad} / \mathrm{s})$ lower than $0.1 \mathrm{MPa}$ (Dahlquist, 1969).

The peel adhesion represents the force required to peel away a patch from a substrate (Cilurzo et al., 2012). The low peel values reported in Table 2 can be considered satisfactory, since it is well known that high values could hurt and cause skin damage upon removal. Because the debonding mechanisms are complex and depend on both the values of $G^{\prime}$ and $G^{\prime \prime}$ and the strain hardening properties in large strain, it is not easy to correlate the peel force to the formulation in a simple way. The $\mathrm{L}-\mathrm{R}$ formulations have a higher modulus at high strain rate and little strain hardening while M-R and H-R are softer (more penetration of the ball) and have some strain hardening (more stable fibrils and higher peel force).

The inclined rolling ball test provided information on the superficial properties of the adhesive. Indeed, differences in the diameter of the balls that stop on the adhesive layer were evident changing SEBS-molecular weight (Table 2) and a correlation among tack and shear adhesion was highlighted: the higher the number of the ball the higher the shear adhesion. The tackifier resin type did not influence the stickiness of the matrices, in accordance with the texture experiments.

In summary, the designed formulations having a low modulus, and therefore satisfying the so-called Dahlquist criterion, appeared suitable to design PSAs. However, their adhesive properties cannot be predicted considering only the linear viscoelastic regimen since they are soft materials. Indeed, the linear viscoelastic properties fail at predicting the cohesive properties of a PSA, which can be studied in the viscoelastic regime. By simple tensile tests it's possible to characterize the ability of the formed fibrils to be stretched before the final debonding. The softening, which occurs at intermediate strains, and the hardening, which occurs at large strains, can be used to predict the mode of failure and the energy of adhesion.

All together the obtained data suggested that all the formulations presented suitable adhesive properties to be used in the design of (trans)dermal patches. First, the shear adhesion values fell within the range which correspond to that of medicated plasters already available on the market (Cilurzo et al., 2013) that in many cases, when tested with the same method used in this work, showed an adhesive failure. Secondly, the peel adhesion values resulted lower than those registered for other formulations based on PSA, but at least the double than plaster based on hydrogels. Thirdly, the stickiness of the patch was sufficiently low to assure an accurate application on the skin (Cilurzo et al., 2012).

\subsection{Drug loaded patches performances}

In order to confirm the feasibility to design transdermal patches made from SEBS, patches loaded with IB were prepared. This active ingredient was selected since it is well recognized that its loading in a polymeric matrix significantly affects the adhesive properties (Cilurzo
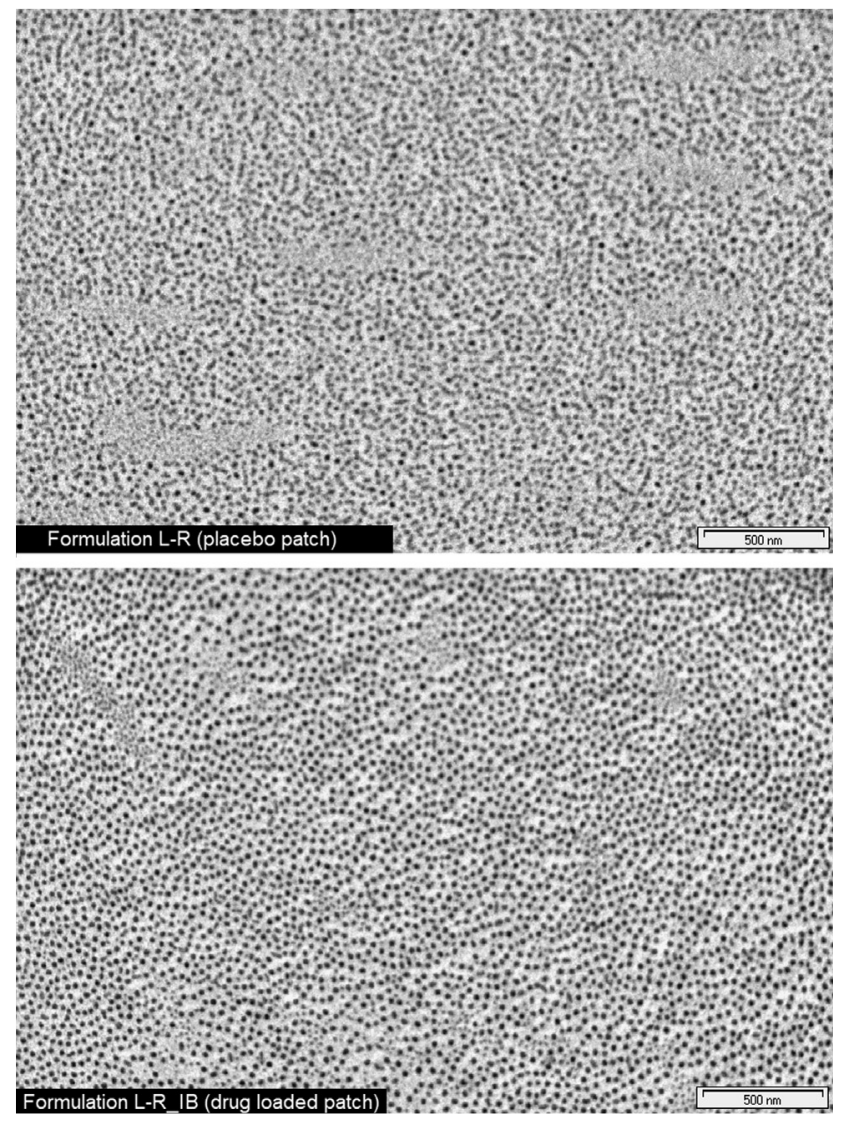

Fig. 5. TEM of L-R and L-R_IB patches.

et al., 2013, 2005; Michaelis et al., 2014). The thickness of the patches was homogenous and in the 49-55 $\mu \mathrm{m}$ range.

An effective reservoir function of these nanostructured systems was highlighted. As depicted in Fig. 5 the structure of the adhesive is not modified by the addition of IB and no-crystal are detected. Indeed, in the case of drugs that are poorly soluble and inclined to crystallize, such as IB, generally the amount that can be loaded in a patch is limited. As a matter of fact, a previous work showed that no more than $3 \%$ IB could be loaded in a polydimethylsiloxane PSA matrix without observing the growth of drug crystals after few days (Cilurzo et al., 2005). Instead, the loaded IB amount in the SEBS based matrices was higher and it didn't require auxiliary excipients (such as crystallization inhibitors), suggesting the ability of the styrenic domains of these copolymers to work as drug reservoirs.

The loading of this large amount of IB in the adhesive matrix significantly influenced the adhesive properties of the patches. Indeed, the rolling ball tack values increased in all cases, while the shear adhesion values significantly decreased, suggesting that this small molecule can effectively act as plasticizer also in SEBS based formulations (Table 4). However, all the patches showed the same failure of the corresponding placebo formulation. In the case of the peel adhesion the effect of the

Table 4

Adhesive properties of drug-loaded patches: shear adhesion, peel adhesion and tack (ball no.) evaluated by inclined rolling ball test.

\begin{tabular}{llll}
\hline Form. Code & Shear adhesion $(\mathrm{min})$ & Peel adhesion $(\mathrm{cN} / \mathrm{cm})$ & Ball No. \\
\hline L-R_IB & $20.8 \pm 0.5$ & $75.8 \pm 9.6$ & 12 \\
L-E_IB & $30.3 \pm 5.3$ & $76.0 \pm 11.7$ & 10 \\
M-R_IB & $5.6 \pm 1.0$ & $42.3 \pm 2.9$ & 12 \\
1M-E_IB & $5.9 \pm 2.3$ & $45.0 \pm 3.8$ & 10 \\
H-R_IB & $5.5 \pm 0.1$ & $36.4 \pm 10.0$ & 15 \\
H-E_IB & $5.8 \pm 0.2$ & $37.0 \pm 10.1$ & 15 \\
\hline
\end{tabular}


drug loading appeared unpredictable, since the values increased for the formulations prepared with SEBS-L, remained substantially unchanged in the case of SEBS-M and significantly decreased for SEBS-H formulations. These modifications may be due to a reduction in the number of entanglements between the polymer chains, which determined an increase in the PSA fluidity, as highlighted by the rheological properties of the formulations. Literature data reported that for chemically cross-linked adhesive matrices the effect of the active ingredient was more evident in the formulations having greater $\mathrm{G}^{\prime}$ values (Wang et al., 2014). Accordingly, the reduction of the shear adhesion values due to the IB loading for SEBS-H formulations having the lowest $\mathrm{G}^{\prime}$ value resulted more evident (about 20 folds) than for SEBS-M formulations (about 10 folds) and SEBS-L (about a half). The opposite trend was found in the case of rolling ball tack test where the plasticizing effect of IB, producing a softer matrix, increased the tack values. Furthermore, the rolling ball tack test also showed the influence of the tackifier resin. This kind of excipients are added to PSAs to modify the viscoelastic properties (decreasing $\mathrm{G}^{\prime}$ values in the low frequency region) so that the adhesive performances in bonding are improved. According to such effect, the formulation based on SEBS-L containing Regalite $^{\mathrm{TM}}$, which, having lower $\mathrm{G}^{\prime}$ value at $0.05 \mathrm{rad} / \mathrm{s}$ appears softer than the corresponding formulation containing Eastotac ${ }^{\mathrm{TM}}$, was more sensitive to the plasticization effect exerted by IB.

Moreover, taking in consideration formulations L-R_IB and L-E_IB, a reduction of shear adhesion values resulted much more evident when Eastotac $^{\mathrm{TM}} \mathrm{H} 100 \mathrm{~W}$ was used, suggesting that in the softer matrices also the $\mathrm{M}_{\mathrm{w}}$ of aliphatic tackifier could play a key role in determining the shear adhesion performances of the patches.

Drug content (Table 5) satisfied the Ph. Eur. assay for the uniformity of dosage units.

IB release was completed within $7 \mathrm{~h}$ and it followed Higuchi pattern independently of the SEBS and tackifier molecular weight $\left(\mathrm{R}^{2}>0.992\right)$. The IB release constants (Table 5), calculated according to the Higuchi model, highlighted as the IB constant release rate was significantly faster by using SEBS-L as polymer $(p<0.05)$, but it was not dependent on the tackifier suggesting that the softening effect, verified in the study of adhesive properties of drug loaded patches, did not influence the drug diffusivity.

These data were in agreement with the rheological pattern: the higher the liquid character of the formulation, the faster the drug release rate. Moreover, comparing these results with the drug release data obtained with a commercially available patch loaded with IB, namely Ibupas $^{\circledast}$, the drug release rate from formulations L-R_IB, L-E_IB and $\mathrm{H}$ E_IB resulted significantly different $(p<0.05)$. In particular, formulations L-R_IB and L-E_IB exhibited faster IB release rate if compared to Ibupas ${ }^{\circledR}$, while in the case of H-E_IB it was slower.

Aiming to deepen the information on the biopharmaceutical performances, in vitro permeation studies by using Franz cells and pig ear skin as membrane were performed on the patches loaded with IB. Drug permeability from the commercial reference product (Ibupas ${ }^{\circledast}$ ) was also evaluated.

The permeated amount after $24 \mathrm{~h}\left(\mathrm{Q}_{24 \mathrm{~h}}\right)$ and flux $(J)$ of IB from the

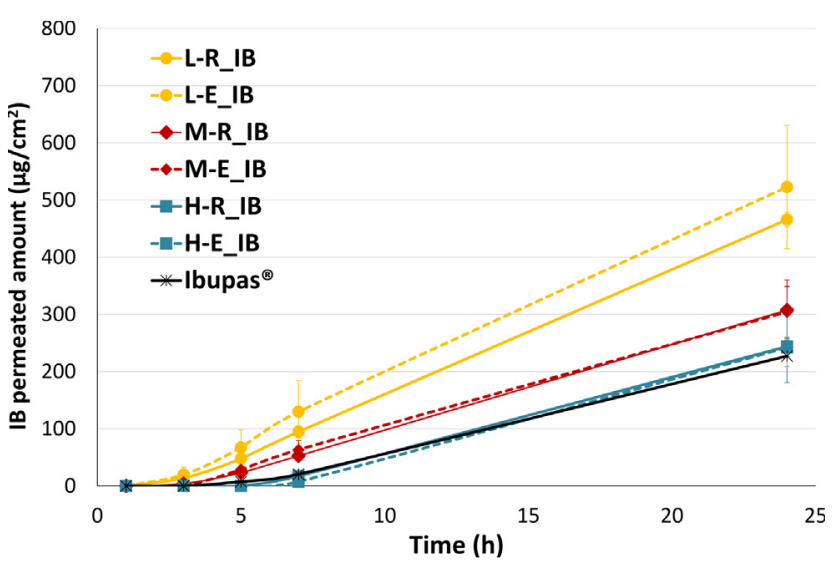

Fig. 6. In vitro permeation profiles of IB through ear-pig skin from the formulated transdermal patches and from the commercial reference product (Ibupas $^{\circledR}$ ).

formulated patches through the pig ear skin are summarized in Table 5. The amount of IB permeated was influenced by polymer molecular weight, but not by the tackifier (Fig. 6): in particular, the lower the polymer molecular weight, the higher the IB permeated amount.

Surprisingly, the IB diffusion through the skin from the formulations L-R_IB and L-E_IB was not limited by the polymeric matrix, if compared to the commercial reference product (Fig. 6). These data well correlated with the results on the drug release from the matrix.

\section{Conclusions}

The tested formulations satisfied the requirements for designing a PSA suitable for the development of transdermal patches, since they exhibited adhesive properties appropriate for an in vivo use and showed satisfactory biopharmaceutical properties. In particular, SEBSlow molecular weight is the polymer most worthy of consideration to design transdermal patches because of its favorable viscoelastic behavior and its capability to not limit in vitro IB permeability, if compared to the commercial reference product. The resins used to confer suitable tackiness to the copolymer did not significantly influence the rheological behavior and adhesive properties of placebo SEBS-matrices. On the contrary, concerning the drug loaded patches, not only the polymer and the resin molecular weight, but also the loaded drug affected the overall technological and in vitro biopharmaceutical properties of the final patch. A plasticizing effect exerted by the drug was evident considering the adhesive properties of the matrices, and it was more evident with formulations based on SEBS-M and SEBS-H (in other words the more elastic materials). However, no sign of cold flow was noticed, confirming the optimal cohesive properties of all these materials.

Finally, the effective reservoir function of the nanostructured styrenic domains of SEBS was confirmed. Indeed, $10 \% \mathrm{w} / \mathrm{w}$ of IB was loaded in these patches, avoiding the drug crystallization, without the addition of auxiliary agents.

Table 5

Drug content and main parameters calculated for in vitro drug release and in vitro skin permeation experiments: constant drug release rate $(k)$, steady flux $(J)$ and cumulative drug amount permeated at the end of the experiments $\left(Q_{24 h}\right)$.

\begin{tabular}{|c|c|c|c|c|}
\hline Form. Code & Drug content $\left(\mu \mathrm{g} / \mathrm{cm}^{2}\right)$ & $k\left(\mathrm{~h}^{0.5}\right)$ & $J\left(\mu \mathrm{g} / \mathrm{cm}^{2} \mathrm{~h}\right)$ & $\mathrm{Q}_{24 \mathrm{~h}}\left(\mu \mathrm{g} / \mathrm{cm}^{2}\right)$ \\
\hline L-R_IB & $674.4 \pm 22.8$ & $0.44 \pm 0.03$ & $21.94 \pm 0.48$ & $465.77 \pm 12.83$ \\
\hline L-E_IB & $688.8 \pm 11.1$ & $0.43 \pm 0.03$ & $23.65 \pm 3.78$ & $522.80 \pm 107.73$ \\
\hline M-R_IB & $773.1 \pm 12.4$ & $0.36 \pm 0.01$ & $15.44 \pm 2.59$ & $307.43 \pm 53.06$ \\
\hline M-E_IB & $734.7 \pm 30.3$ & $0.36 \pm 0.03$ & $14.39 \pm 2.04$ & $304.32 \pm 44.68$ \\
\hline H-R_IB & $573.1 \pm 17.5$ & $0.33 \pm 0.01$ & $13.03 \pm 3.30$ & $243.81 \pm 63.08$ \\
\hline H-E_IB & $586.5 \pm 5.1$ & $0.31 \pm 0.01$ & $13.21 \pm 0.86$ & $241.84 \pm 15.45$ \\
\hline Ibupas $^{\circledast}$ & $*$ & $0.35 \pm 0.01$ & $11.79 \pm 4.62$ & $227.04 \pm 7.98$ \\
\hline
\end{tabular}

*: not determined. 
Thus, the overall data suggested that SEBS copolymers are suitable materials to prepare drug in-adhesive patches by the casting technique.

\section{CRediT authorship contribution statement}

Chiara Grazia Milena Gennari: Conceptualization, Investigation, Formal analysis, Writing - original draft, Visualization. Gaia Maria Giorgia Quaroni: Conceptualization, Investigation, Formal analysis, Writing - original draft, Visualization. Costantino Creton: Formal analysis, Writing - review \& editing, Supervision. Paola Minghetti: Conceptualization, Supervision. Francesco Cilurzo: Conceptualization, Methodology, Formal analysis, Writing - review \& editing, Visualization.

\section{Declaration of Competing Interest}

The authors declare that they have no known competing financial interests or personal relationships that could have appeared to influence the work reported in this paper.

\section{References}

Bates, F.S., Fredrickson, G.H., 1990. Block copolymer thermodynamics: theory and experiment. Annu. Rev. Phys. Chem. 41, 525-557.

Campani, V., Biondi, M., Mayol, L., Cilurzo, F., Franzé, S., Pitaro, M., De Rosa, G., 2016. Nanocarriers to enhance the accumulation of vitamin K1 into the Skin. Pharm. Res. 33 (4), 893-908.

Chanda, M., Roy, S.K., 2007. Plastics Fundamentals, Properties, and Testing, Characteristics of Polymers, first ed. CRC Press, Boca Raton (FL) Chapter 1.

Cilurzo, F., Minghetti, P., Casiraghi, A., Tosi, L., Pagani, S., Montanari, L., 2005. Polymethacrylates as crystallization inhibitors in monolayer transdermal patches containing ibuprofen. Eur. J. Pharm. Biopharm. 60 (1), 61-66.

Cilurzo, F., Gennari, C.G.M., Minghetti, P., 2012. Adhesive properties: a critical issue in transdermal patch development. Exp. Opin. Drug Deliv. 9 (1), 33-45.

Cilurzo, F., Gennari, C.G.M., Selmin, F., Franzè, S., Musazzi, U.M., Minghetti, P., 2013. On the characterization of medicated plasters containing NSAIDs according to novel indications of USP and EMA: adhesive property and in vitro skin permeation studies. Drug Dev. Ind. Pharm. 41 (2), 183-189.

Costa, P., Ribeiro, S., Botelho, G., Machado, A.V., Lanceros-Mendez, S., 2015. Effect of butadiene/styrene ratio, block structure and carbon nanotube content on the mechanical and electrical properties of thermoplastic elastomers after UV ageing. Polym. Test. 42, 225-233.

Creton, C., Roos, A., Chiche, A., 2005. Effect of the diblock content on the adhesive and deformation properties of PSAs based on styrenic block copolymers. In: Possart, W. (Ed.), Adhesion: Current Research and Application. Wiley-VCH, Weinheim, (G), pp. 337-364.

Creton, C., Hu, G.J., Deplace, F., 2009. Large-Strain mechanical behavior of model block copolymer adhesives. Macromol. 42, 7605-7615.

Dahlquist, C.A., 1969. Treatise on adhesion and adhesives. In: Patrick, R.L. (Ed.),
Pressure-sensitive adhesives. Marcel Dekker, Inc, New York, pp. 219-260.

Deplace, F., Carelli, C., Mariot, S., Retsos, H., Chateauminois, A., Ouzineb, K., Creton, C., 2009. Fine tuning the adhesive properties of a soft nanostructured adhesive with rheological measurements. J. Adhes. 85 (1), 18-54.

Derail, C., Cazenave, M.N., Gibert, F.X., Marin, G., Kappes, N., Lechat, J., 2004. Rheological properties of hot-melt pressure-sensitive adhesive (HMPSAs) based on styrene-isoprene copolymers. Part 2: Innovative molecular design form predictive formation. J. Adhes. 80 (12), 1131-1151.

Engesland, A., Škalko-Basnet, N., Flaten, G.E., 2016. In vitro models to estimate drug permeation through the compromised stratum corneum barrier. Drug Dev. Ind. Pharm. 42 (11), 1742-1751.

Gennari, C.G.M., Selmin, F., Franzè, S., Musazzi, U.M., Quaroni, G.M.G., Casiraghi, A. Cilurzo, F., 2017. A glimpse in critical attributes to design cutaneous fil forming system based on ammonium methacrylate. J. Drug Deliv. Sci. Technol. 41, 157-163.

Hou, J., Shi, Q., Ye, W., Fan, Q., Shi, H., Wong, S.C., Xu, X., Yin, J., 2014. Construction of 3D micropatterned surfaces with worm like and superhydrophilic PEG brushes to detect dysfunctional cells. ACS Appl. Mater. Interferences. 6 (23), 20868-20879.

Jagisch, F.C., Tancrede, J.M., 1989. Styrenic block copolymers. In: Satas, D. (Ed.), Handbook of pressure sensitive adhesive technology. Warwick, Rhode Island, pp. 346-398.

Jin, S.G., Yousaf, A.M., Kim, K.S., Kim, D.W., Kim, D.S., Kim, J.K., Yong, C.S., Youn, Y.S., Kim, J.O., Choi, H.G., 2016. Influence of hydrophilic polymers on functional properties and wound healing efficacy of hydrocolloid based wound dressings. Int. J. Pharm. 501 (1-2), 160-166.

Kim, J.-H., Kim, H.-G., Lim, J.-C., Cho, K.-S., Min, K.-E., 2012. Thermal properties and adhesion strength of amorphous poly( $\alpha$-olefins) /styrene-ethylene-butylene copolymer/terpene hot-melt adhesive. J. Appl. Polym. Sci. 124 (4), 3312-3319.

Lakrout, H., Sergot, P., Creton, C., 1999. Direct observation of cavitation and fibrillation in a probe tack experiment on model acrylic pressure-sensitive-adhesives. J. Adhes. 69 (3-4), 307-359.

Ma, J., Wang, C., Luo, H., Zhu, Z., Wu, Y., Wang, H., 2013. Design and evaluation of a monolithic drug-in-adhesive patch for testosterone based on styrene-isoprene-styrene block copolymer. J. Pharm. Sci. 102 (7), 2221-2234.

Michaelis, M., Brummer, R., Leopold, C.S., 2014. Plasticization and antiplasticization of an acrylic pressure sensitive adhesive by ibuprofen and their effect on the adhesion properties. Eur. J. Pharm. Biopharm. 86 (2), 234-243.

Minghetti, P., Casiraghi, A., Cilurzo, F., Montanari, L., 2001. Evaluation of adhesive properties of transdermal therapeutic systems containing nitroglycerin. Boll. Chim. Farm. 140 (2), 63-67.

Minghetti, P., Cilurzo, F., Casiraghi, A., 2004. Measuring adhesive performance in transdermal delivery systems. Am. J. Drug Deliv. 2 (3), 193-206.

Nakajima, N., Babrowicz, R., Harrell, E.R., 1992. Rheology, composition, and peel-mechanism of block copolymer-tackifier-based pressure sensitive adhesives. J. Appl. Polym. Sci. 44 (8), 1437-1456.

Nase, J., Derks, D., Linder, A., 2011. Dynamic evolution of fingering patterns in a lifted Hele-Shaw cell. Phys. Fluids 23 (12), 123101. https://doi.org/10.1063/1.3659140.

Pagani, S., Di Grigoli, M., Comuzio, S., 2006. Self-adhesive matrix system comprising a styrene block copolymer. United States patent US 20110243985 A12011.

Quaroni, G.M.G., Gennari, C.G.M., Cilurzo, F., Ducouret, G., Creton, C., Minghetti, P., 2017. Tuning the rheological properties of an ammonium methacrylate copolymer for the design of adhesives suitable for transdermal patches. Eur. J. Pharm. Sci. 111, $238-246$.

Wang, J., Zhang, H., An, D., Yu, J., Li, W., Shen, T., Wang, J., 2014. Rheological characterization of cataplasm bases composed of cross-linked partially neutralized polyacrylate hydrogel. AAPS PharmSciTech. 15 (5), 1149-1154. 